\title{
THE ANALYSIS OF THE MEANING OF THE PERSON'S INTERNAL WORLD AS A BASIS OF SELF-EFFICACY IN THE EDUCATIONAL SYSTEM
}

\author{
Fatima Tashimova ${ }^{1}$, Aidana Rizulla ${ }^{1}$, Galiya Ibrayeva ${ }^{1}$, Gulnar Abdullina ${ }^{2}$, Bakhtiyar \\ Nurumov $^{3}$ \\ ${ }^{1}$ Al-Farabi KazNU, pr. al Farabi, 71, 050040 Almaty, Republic of Kazakhstan \\ ${ }^{2}$ Kazakh Humanitarian and Law Innovative University, ul. Mangilik el, 11, 071400, Semey, \\ Kazakhstan \\ ${ }^{3}$ SuleymanDemirel University, Ablayhan st., 1/1, 040900, Kaskelen, Almaty, Kazakhstan
}

\begin{abstract}
The formation of the subject of the education system is inextricably linkedwith factors of self-knowledge and self-awareness that includes the knowledge of one's own inner world. The inner world was associated with mental processes, conscious and unconscious factors, feelings and emotions, semantic reality. In recent years, in connection with the understanding of a person as a collective phenomenon, the inner world begins to be perceived as a representation of significant others. In particular, in psychoanalysis it is the representation of parents, in individual psychology it is siblings, in analytical psychology it is a multitude of personalities, up to the first man, that determine the formation of subjectivity. Based on this, we define the inner world not just as a semantic reality, but a reality for the production of meanings, provided by the cooperation of all the intimate personalities represented in one person, with whom she/he interacts directly and indirectly.Based on this, we propose a semantic analysis of the inner world, which involves the identification of a system of significant personalities, the subjective reflection of their values and actions, the study and rethinking of positive and negative influences that ensure the formation of new meanings.
\end{abstract}

\section{Introduction}

One of the significant factors determining person's self-efficacy in the education system is a semantic analysis of the inner world of the individual. Understanding the inner world is inextricably linked with the definition of a person as an integral and systemic phenomenon, as a multicomponent world. Unfortunately, today psychologists have no consensus on understanding a person as a collective phenomenon. The problem of the a person as a collective phenomenon was developed in the works of S.L. Rubinstein [1]. However, to this day, his ideas are not sufficiently disclosed in the vein that is posed in his works. To some extent, the subject is understood as a group [2-3], however, it is not disclosed which groups

\footnotetext{
*Corresponding author: fatima_tashimova@mail.ru
} 
are represented in the person [4-5]. In this regard, there is a great variety of contents of the person's inner world as an individual subject, ontogenetic subject, and phylogenetic subject. And, unfortunately, all this is at the level of statement and theorizing. In this regard, the definition of the inner world is characterized by a fairly wide variety and, accordingly, uncertainty, for example, the inner world as defined by parental introjects is presented in psychoanalysis [6-7], as a result of relationships with siblings in individual psychology [8], as the representation of ancestors before the first person in analytical psychology [9], as semantic reality [10]. Thus, the understanding of the inner world is characterized by an emphasis on certain systems: introjects of parents, simbling, ancestors, while all these systems are presented in the person holistically.

In this regard, the initial studies of this problem we can find in the concept of alFarabi [11], who described "a person as a microcosm, in which the entire macrocosm is represented" referring this idea we define a person as a representer of many personalities that regulates and integrates all structural components: substantial and instrumental. Proceeding from this, the inner world of a person is understood as an intimate, holistic, sacred, structured by the importance of the intimate personalities represented in it, acting as accomplices in the process of meaning-creation [12].

What is an intimate person? An intimate person has nothing to do with the object of sexual partnership, especially since sex in people's lives is bare to beyond limits. The concept of "intimate" refers to the sacred and hidden. Based on this, an intimate person is a subjectively reflected, with all the positives and negatives, not presentable to the outside world and not verbalized out loud, an image of a significant person that shimmers with different facets in different situations. Concealment, sacredness, concealment from another person and little awareness of the personalities represented ensure the intimacy of the inner world. Only the inner world of a human being is intimate, which is hidden from the other people and the access to this world is allowable only him/her. In the inner world is characterized as a platform of free reflection, where a person is the only master of his/her thoughts, experiences, the images of intimate personalities and existing being constructed by him/her (a subjective picture of the world). The people who surround the person can comprehend his/her inner world through the analysis of actions, deeds and projections. These are intimate personalities that stimulate us, to certain deeds, "going beyond ourselves" to overcome, as well as reasonable protection as "some stop in time", related to deepening the essence of things and phenomena and ensuring the removal of all unnecessary, useless, superficial and empty in the process of meaning formation. As you can see, in the inner world there is no death. Both surviving people and people who have left for another world continue to invisibly influence all the choices of a person. The inner world is the life of others in a person and their co-creation, associated with the production of meaning, stimulating overcoming life difficulties.

Intimate personalities of the inner world take an invisible part in the process of correlation, the choice of emphasis on a particular measure of the manifestation of certain values and stimulate the processes of meaning formation and realization of meaning.

In this regard, the inner world is not just a semantic reality [10], it is a reality of the production of meaning. The question is "Who makes a sense?"A person and many intimate personalities living in his inner world (both living and "departed"), as well as favorite objects of material and surrounding nature that determine the production of meaning. In this regard, the methodology of semantic analysis is aimed at identifying the subjective reflection of various intimate personalities, comprehending and understanding their actions and values, positive and negative contributions, realizing and developing a new look from today's realities, developing and forgiving traumatic situations, as well as blessing and appreciation the positive experience. 
We proceed from the assumption that the study of unresolved conflicts, experiences of the inner world, through semantic analysis, will allow us to develop a new attitude not only to significant individuals, but also to ourselves, to our resources, which will ensure the success of self-actualization and stimulate the development of productive coping strategies that encourage students to better master the system of knowledge and information, process them, as appropriate, and implement them into the practice.

\section{Research methods and procedure}

254 students from various universities in Almaty participated in the study. Studywere conducted from 2010 to 2019. The structure and content of the inner world was considered in terms of the representation of the following intimate personalities: mother, father, siblings, loved one, friends, teachers, enemies and subjects of the virtual world.

A substantial analysis of the representation of intimate personalities was carried out using the technology of "Semantic analysis of the subject's inner world" [13]. This technique is performed during one semester in independent lessons with the teacher. The technology of work includes the following: 1)The participants graphically draw a system of significant personalities for them, including both positively and negatively represented. 2) Clarifying the contribution measure of each character into his/her life, reflecting a correlated system of values, defining certain meanings that contributed to overcome the difficult situations. 4. Analyze the perception of traumatic situations, forming a new look that provides understanding, forgiveness and repentance. 5. Conclusions for selfimprovement.

The system of significant people includes not only loved ones, but also enemies, the analysis of the influence of which is essential. As a result, students' various visions of their self-concept, a multiple world of intimate personalities and their values, were obtained and discovered. Each of the personalities introduced his own system of values and was reflected in various colors.

Before and after the semantic analysis, the measurement of the dependent variables were conducted using the following questionnaires: 1) Self-actualization of the personality (N.F. Kalin), adapted version (A.V. Lazukina) [14]. 2) AdolescentCopingScale (ACS) offered by E. Freidenberg and R. Lewis, adapted by T. L. Kryukova [15]. The data went through the factor analysis using the "Principal Components" method.

\section{Results and discussion}

During the introspection, students noted a very strong influence of defense mechanisms. This is a completely normal situation, since they worked with the most intimate world for a person. In this regard, it was rather difficult for students. Therefore, the defense stimulated the reflection of its significant personalities more often from the positive side. Parents were more often reflected positively, with an emphasis on their best side. But there were those who did not include them in their system, in connection with various kinds of offenses against them. Mother and father are represented as shrines, despite all their shortcomings $(58 \%)$. However, the father was more likely to fall into the category of neutral $(19 \%)$ and negatively represented (among $23 \%$ of students he was reflected as a "traitor", as "leaving children to the mercy of fate", as "incapable of finding his own way", etc. ).

The importance of a loved one goes after the parents. For most students, it is presented as a stimulating ability to love, create, improve, trust. In $25 \%$ of students who experienced a relationship disorder, sublimation of $15 \%$ (leaving for creativity, study, work), $10 \%$ avoidance, fear of love, distrust of the world have become a value. Friends are presented as a resource of an understanding, stimulating self-actualization and healthy 
rivalry. Negative version of the friendsrepresentation (manipulation, betrayal). Brothers and sisters were represented as loving and revealing potentialities. Only $24 \%$ of the participants perceived siblings as rivals, stimulating achievements. Enemies (people who are unpleasant to them and who feel discomfort) stimulate stress resistance and competitiveness according to the positions of the participant.

In the great importance are idols from different centuries and countries mediated by the Internet. The strength of their influence, sometimes exceeds the strength of the immediate environment, due to the fact that they are reflected by the participant as being close in spirit, significant as a model of behavior and stimulating high self-esteem. The revealed effects of idols are important in the context of globalization, when there is a struggle for the consciousness and values of a person, which can give rise to various effects and consequences, in the process of his creative adaptation in this many-sided world. The special significance of these idols is determined by the influence on the deep processes of sense formation, at the unconscious level thataffect the relationships with others. Idols most often reflected idealized, unlike representatives of the immediate environment. Therefore, it was important to highlight their positive and negative sides. Along with idols, communities from social networks, on which significant time was spent also had a great influence.

The significant systems and the measure of their value were determined by the principle of "approximation-removal", reflecting the level of identification and alienation. Identification is a mechanism of involvement with many intimate personalities (from merging to assimilation), which determines the measure of acceptance of the values of the represented personalities. Alienation is a mechanism of detachment (from detachment to hostility), which determines the measure of values rejection of the represented individuals.

A measure of the manifestation of identification and alienation mechanisms with intimate personalities allows us to predict the state of the inner world. Finding a measure is always a complicated process, starting with throwing from one extreme to the other "the white and black" categorization, which in the process of life comes to the definition of some measure. The failure to find a measure means a different nature of personality accentuation, distortions in self-improvement and communication, as well as adaptability to the world. Taking this into account, this stage of the analysis allows us to state contradictions or a measure of consistency in the values of various intimate personalities that reflect the person's ability to find one's own measure of manifestation of various human needs in solving various problems and their implementation. The purpose of a psychologist at this level is the stimulation of harmony in the choice of a measure by the person that provides the most effective ways to implement the solution.

In addition to the protective mechanisms, the difficulty comes from the ability to reflect adequately the intimate personalities, with all the pros and cons. In the process of this work, students updated the most significant events encountered in their life that caused a storm of various emotions, both positive and negative, which affected the time of the work. Therefore, participants emphasized that evoking some of the past events made them cry. If they expected to complete the work in two hours, as they admitted, then it dragged on for a whole week, when they again and again returned to the analysis of their relationship. Actualization of negative situations suggested a review of the situation from the point of view of the modern self. In this regard, many students in the work process reframed their vision of the event, of the other person and themselves, forming a new attitude towards them, which contributed to forgiveness and completion of gestalt. We offer a variant of a schematic representation of a semantic analysis of a person's inner world. Their "proximity - range" was provided by the measure of values acceptance of the intimate personalities and the possibilities of stimulating the process of creating and overcoming difficult life situations. 


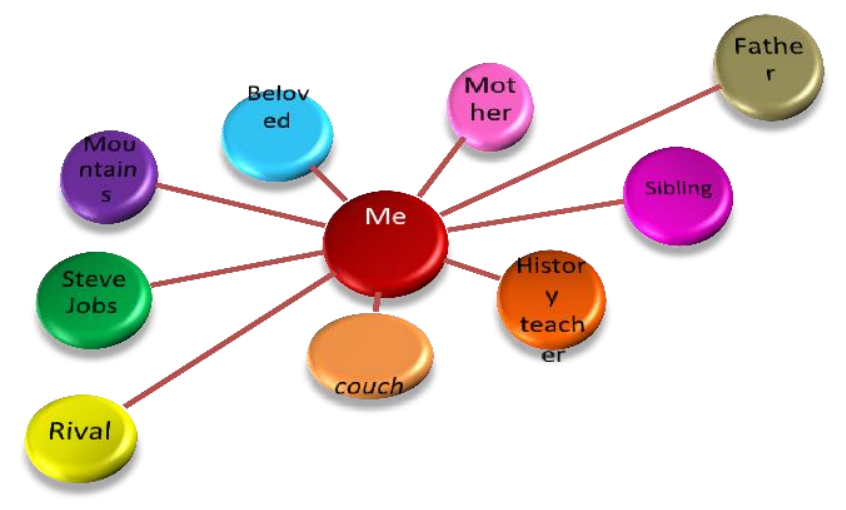

Fig 1. The meaning analysis of the person's internal world.

Noting the features and the significance of the inner world semantic analysis points out on the importance and effectiveness of this analysis. Referring to this, we consider are emphasizing the value of the semantic analysis that influenced the students' selfactualization.

The results of factor analysis allowed us to establish the determining factor reflecting the students' self-actualization before semantic analysis is represented by the following indicators: Need for knowledge (0.521), autonomy (0.499), a look at human nature (0.464), autosympathy (0.397), values $(0.381)$.

Analysis of the indicators allows us to talk about the decisive role of cognition in the process of self-actualization. The meaning of knowledge is provided by the correlation of needs for independence, faith in the disclosure of potential human resources, sympathy for oneself and orientation to the values of actualizing personalities.

After a semantic analysis, the determining factor of self-actualization is represented by the following indicators: Need for cognition (0.612), self-understanding (0.568), contact $(0.502)$, autosympathy $(0.478)$, time orientation $(0.473)$, spontaneity $(0.443)$. The determinant of self-actualization is cognition. However, its meaning is determined by the ratio of needs: self-understanding, establishing productive relationships with others, autosympathy and organizing the life time according to the principle of "here and now". The results of a comparative analysis of the factors are reflected in Fig. 2. (See Figure 2)

Thus, a comparative analysis of the impact of working with the inner world allows us to state significant changes in students' self-actualization strategies regarding spontaneity $[\mathrm{P}<0.01]$, self-understanding [ $\mathrm{P}<0.01]$, contact $[\mathrm{P}<0.01]$, creativity $[\mathrm{P}<0.05]$, determining students' self-efficacy.

What changes have occurred in coping strategies? Here we consider the results of factor analysis according to the methods of Freidenberg and Lewis, adapted by $\mathrm{T}$. Kryukova (See table 1) 


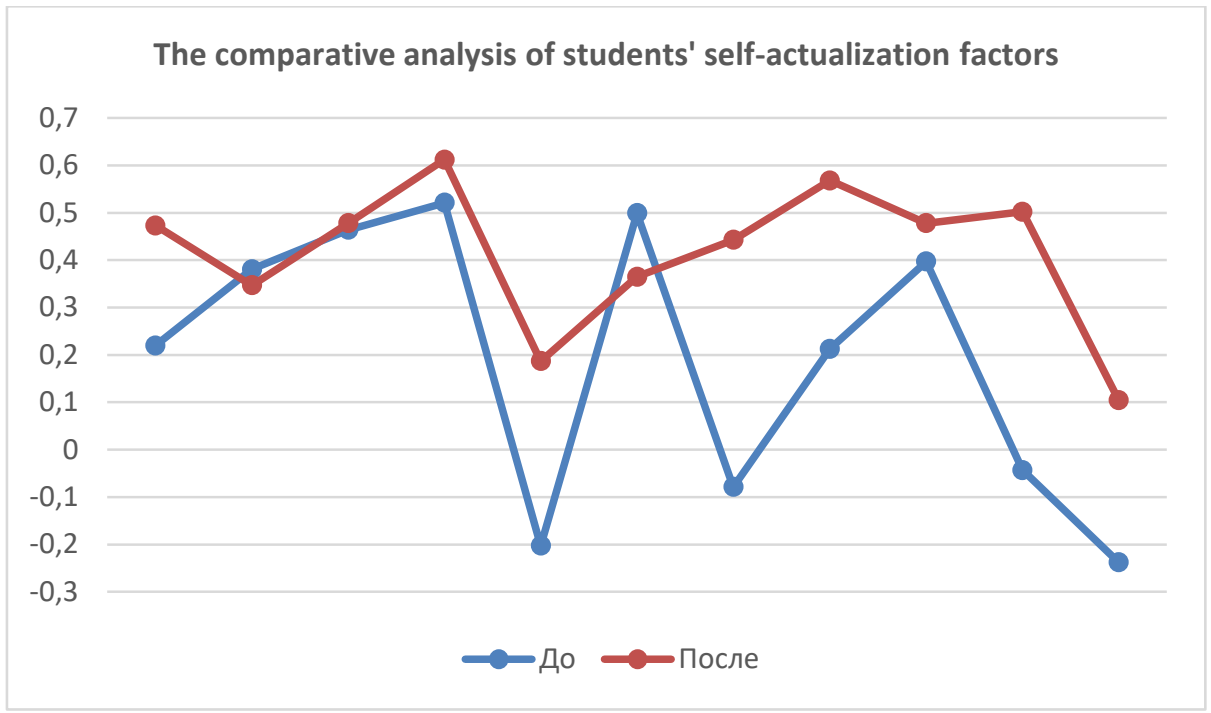

Fig. 2.Before and after semantyc analysis 1.Orientation in time; 2. Values; 3 . A look at the nature of man; 4. The need for knowledge; 5. Creativity; 6. Autonomy; 7. Spontaneity: 8. Self-understanding; 9. Auto-sympathy; 10. Contact; 11 Flexible Communication

The factor analysis results allowed us to establish that the determining factor that reflects coping strategies before conducting semantic analysis is represented by the following indicators: Focus on problem solving (0.494), desire to distract and relax, entertainment in society $(0.450)$, friends $(0.413)$, search for support and approval $(0,409)$, hard work and achievements (0.407), discharge - "releasing steam" $(0.372)$, hope for a miracle (0.369), self-incrimination and personal responsibility for problems $(0,362)$. The indicators analysis allows to state the focus on overcoming a difficult situation by focusing on solving a problem associated with rest and support of friends, as well as the likelihood of a miracle. We can call this style as a socially oriented style.

The determining factor reflecting coping strategies after conducting a semantic analysis is represented by the following indicators: Focusing on the positive (0.698), hard working and achievements (0.559), searching for spiritual support (0.490), ignoring, blocking problems (- 0.474), non-possession, refusal to act $(-0.462)$, focusing on solving problems $(0,352)$, activities (playing sports, maintaining health $(0.451)$, friends $(0,399)$.

The indicators analysis of allows to talk about focusing on a positive sides, effective implementation, coupled with overcoming protective mechanisms. The name of this style is "problem-oriented".

A comparative analysis of coping strategies (see Fig. 3) allows to state that after a semantic analysis, positive thinking $[\mathrm{P}<0.01]$ is directed towards solving a problem and achieving goals $[\mathrm{P}<0.01]$, overcoming defense mechanisms $[\mathrm{P}<0.05]$, the conscious organization of leisure and the realization of resources. 
Table 1.The results of factor analysis of strategies for students' coping behavior

\begin{tabular}{|c|c|c|c|}
\hline \multirow[t]{2}{*}{ No } & \multirow[t]{2}{*}{ Copying strategies } & $\begin{array}{l}\text { Results of factor analysis } \\
\text { of copying strategies }\end{array}$ & \\
\hline & & Before & After \\
\hline 1 . & $\begin{array}{l}\text { S1 -Searching for the } \\
\text { support and approval }\end{array}$ & 0,409 & 0,223 \\
\hline 2. & $\begin{array}{l}\mathrm{S} 2 \text { - Focusing on the } \\
\text { problem solving }\end{array}$ & 0,494 & 0,352 \\
\hline 3. & $\begin{array}{l}\text { S3 - Hard working and } \\
\text { achievements }\end{array}$ & 0,407 & $\mathbf{0 , 5 5 9}$ \\
\hline 4. & S4 - Anxiety & 0,395 & $-0,137$ \\
\hline 5. & S5 - Friends & 0,413 & 0,399 \\
\hline 6. & S6 - belongingness & 0,151 & 0,096 \\
\hline 7. & S7- Hope for a miracle & 0,369 & 0,221 \\
\hline 8. & S8 - Failure, refusal to act & $-0,003$ & $-0,462$ \\
\hline 9. & $\begin{array}{c}\text { S9 - Discharge - } \\
\text { "steamrelease" }\end{array}$ & $\mathbf{0 , 3 7 2}$ & 0,112 \\
\hline 10. & $\begin{array}{l}\text { S10 - seeking support by } \\
\text { organizing group } \\
\text { activities. }\end{array}$ & $-0,118$ & $-0,179$ \\
\hline 11. & $\begin{array}{l}\text { S11 - Ignoring, blocking } \\
\text { the problem }\end{array}$ & 0,291 & $-0,474$ \\
\hline 12. & $\begin{array}{l}\text { S12 self-incrimination and } \\
\text { personal responsibility for } \\
\text { problems }\end{array}$ & 0,362 & 0,285 \\
\hline 13. & $\begin{array}{l}\text { S13 - Detachment } \\
\text { (refusal to devote others to } \\
\text { their cares) }\end{array}$ & $-0,061$ & $-0,015$ \\
\hline 14. & $\begin{array}{l}\text { S14 - Search for spiritual } \\
\text { support, orientation to } \\
\text { religious support }\end{array}$ & 0,205 & 0,490 \\
\hline 15. & $\begin{array}{c}\mathrm{S} 15 \text { - Focusing on the } \\
\text { positive sides }\end{array}$ & 0,322 & 0,698 \\
\hline 16. & $\begin{array}{c}\text { S16 - Searching help from } \\
\text { specialists }\end{array}$ & $-0,010$ & $-0,202$ \\
\hline 17. & $\begin{array}{l}\text { S17 - The desire to } \\
\text { distract and relax, } \\
\text { entertainment in society }\end{array}$ & $\mathbf{0 , 4 5 0}$ & 0,302 \\
\hline 18. & $\begin{array}{l}\text { S18 -activities (sports, } \\
\text { maintaining health) }\end{array}$ & 0,306 & 0,451 \\
\hline
\end{tabular}




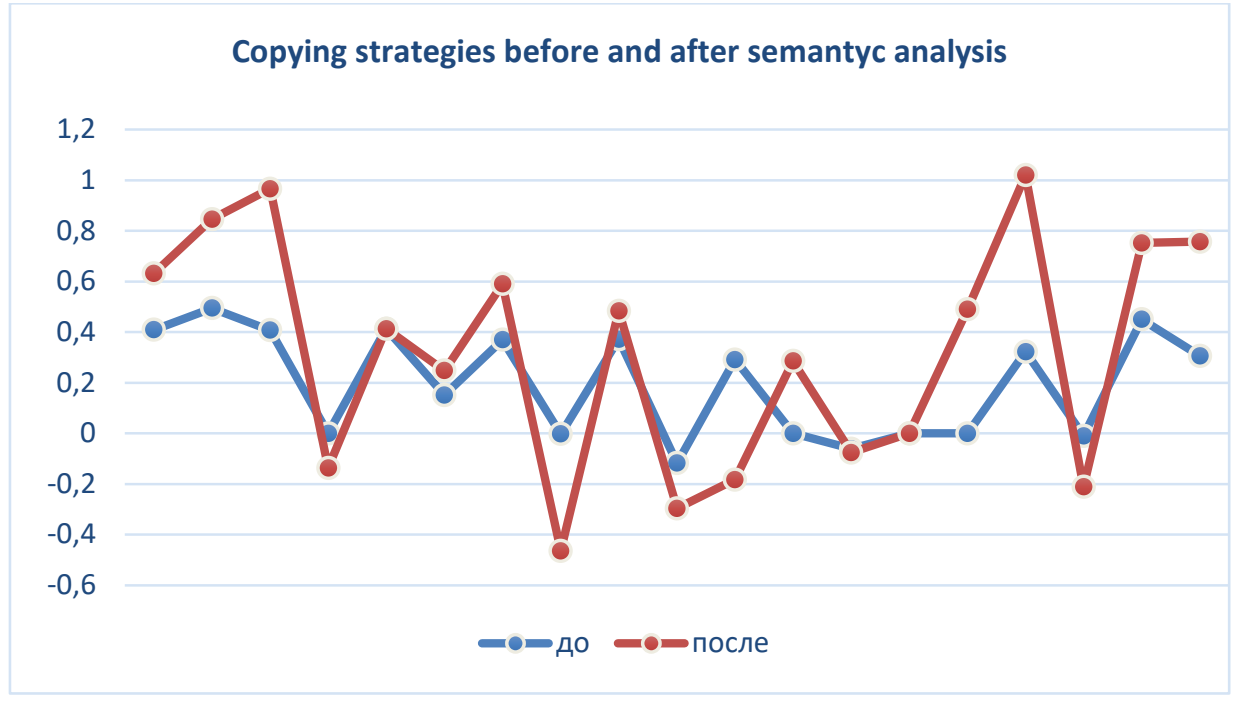

Fig 3. Coping strategies before and after semantic analysis.

Coping strategies before and after semantic analysis: S1 - search for support and approval S2 - Focus on solving problems S3 - Hard work and achievements S4 - Anxiety and anxiety - S5 - Friends S6 - Feeling of belonging S7 - Hope for a miracle — S8 Non-conquest, refusal of actions S9 - Discharging - "releasing steam S10 - seeking support by organizing group actions S11 - Ignoring, blocking problems S12 self-blaming and personal responsibility for problems S14 - Seeking spiritual support, orientation to religious support S15 - Focusing on the positive sides, S16 - Help of specialists S17 - The desire to escape and relax, entertainment in society) S18 - outdoor activities (sports, health maintenance).

\section{Conclusions}

1. The inner world is an intimate, deep, sacred sphere with intimate personalities uniquely reflected by a person, their positive and negative values, actions, contributions to joint meaning-making, most often in a person's life without any particular attention. A man runs through the life and is not able to delve into the inner world. Nevertheless, it is precisely that all the reasons and strategies of our behavior the foundations of our self-efficacy in the outside world are rooted into the inner world. We delve into the inner world when emergencies occur and we do not have a systematic way of the analysis. In this regard, the method of semantic analysis of the inner world that based on the ideas of al-Farabi, assumes the integrity and systematic analysis, and not "grabbing" of its constituent entities separately. It is aimed at analyzing who and how is represented, what values and deeds and what reflection has taken in the deep layers of emotions, values that stimulate our behavior. Working with the inner world and intimate personalities living there, we learn to find the measure in our choices and actions, realizing the invisibility of their presence, stimulating the voice of our conscience. The work of the inner world is deeply intimate and only there, a person is the master of his/her reflections, positions, choices and the reasons for the actions, without embellishment and excuses. This is undistorted reality for the owner. Another thing is how the person presents it to the others and the world. Therefore, the actualization of the problems of the inner world is of value, from the point of view, of a timely revision of values and actions in order to timely change the situation, apologize, 
forgive and repent. The analysis of the inner world presupposes not only the integration of values, but also the systemic coherence of all spheres of a person's life, determined by the intimate personalities of the inner world, depending on their significance, stimulating meaning formation and overcoming difficult life situations.

Thus, work with a semantic analysis of the inner world has not only a cognitive, emotional, but also a therapeutic effect. Work with the values and contributions of intimate personalities, as well as ways to overcome life's difficulties, allowed students to realize their integrity, their own values, the importance of others and themselves, as well as the inseparability of their personal self with others. This was an incentive for them, now, and not after their "departure", to "find" their parents, opening them from new faces, sending them letters of recognition and gratitude, letters of forgiveness and love.

2. The results of introspection were truly productive in terms of stimulating the revision of self-actualization strategies from the "I as the world" orientation, in which the subjects were focused only on themselves, on their movement and achievement in the world, after a semantic analysis, in addition to focusing on their own goals. They focused on the formation of the ability to build productive relationships with the world, on the harmonization of the "I and the world" relations, which creates more opportunities for selfefficiency.

The understanding of the time factor was essential. Probably, it was the factor that stimulated the reduction of time spent on communities from social networks (Facebook, Instagram, etc.). After a semantic analysis, awareness and control of the temporal structure of life was one of the students' achievements.

3. A comparative analysis of coping behavior strategies before and after semantic analysis also allows to talk about a revision of a socially oriented style for more productive options for coping strategies focused on solving a problem. Particularly, strategies for positive perception of situations, focusing on problem solving, controlling the manifestation of protective mechanisms and purposeful leisure activities were updated

\section{References}

1. S. L. Rubinstein. The problems of general psychology, M.: Pedagogy, 365 p. (1949)

2. A.V. Brushlinskiy. Personality psychology, SPb.: Alteya, 234 p. (2003)

3. A.L. Zhuravlev, The psychology of collective personality, M.: PER SE, 51 (2002)

4. V.B. Shvyrkov. Introduction into objective psychology, M.: Psychology Institute RAN, 223 p. (1995)

5. P.I. Maximova, O.A. Alexandrov, I.V. Tichomirova, E.V. Filippova, L Fomicheva, Psych. J., 25, 17 (2004)

6. S. Freud. Dostoevsky and patricide, M.: Olimp, 413 (1997)

7. S. Freud. Leonardo da Vinci, Exmo Press, 251 (2005)

8. A. Adler. Practice and theory of an individual psychology, 296 p. (1994)

9. K. Jung. Analytical psychology, 71 (1994)

10. D.A. Leontiev. Psychology of the meaning, thesis, 535 p. (1999)

11. Al-Farabi. Abouthappiness, AlmaAtaPress, 275 p. (1973)

12. F.S. Tashimova, A.R. Rizulla, The problem of person's meaning construction as a multiface world, Laplambert Academic Publishing GmbH\&Co, 385 p. (2012)

13. F.S. Tashimova, A.R. Rizulla,Int.Conf.Ed. Method. Un., 264 (2017)

14. N.F. Kalin. J Psych.Tests, 122 (2003)

15. T.L. Kryukova. Methods of copying behavior study, Avintitul Press, 60 p. (2007) 